\title{
Pressure Relief of Non-Ideal Mixtures: Composition Trajectories \& Residue Curve Maps
}

\author{
Paul Dillon ${ }^{1}$ \\ ${ }^{1}$ PM Group Ltd.
}

May 6, 2020

\begin{abstract}
During the course of a pressure relief discharge from a vessel containing a multicomponent liquid mixture, composition changes occur that affect the properties vessel contents. In this work, a model of the dynamic relief process for ternary, non-ideal, homogeneous mixtures is developed, under the assumption of vapour-only venting. Opening/re-closing of the relief valve introduces state-events which require re-initialization of the model at each state transition. The relationship between the pressure relief model and the concept of residue curves, which describe simple-distillation processes, is demonstrated. It is known that the presence of azeotropes and distillation boundaries in mixtures restricts the composition trajectories of simpledistillation processes, as well as continuous distillation columns at total reflux. In this work, the residue-curve analogy is extended to vapour-only pressure-relief, where vapour composition changes directly affect the operation of the pressure-relief device. Examples of dynamic relief processes are developed for ternary mixtures with varying non-ideality.
\end{abstract}

\section{Hosted file}

ReliefPaper.tex available at https://authorea.com/users/317367/articles/448814-pressurerelief-of-non-ideal-mixtures-composition-trajectories-residue-curve-maps

(a)

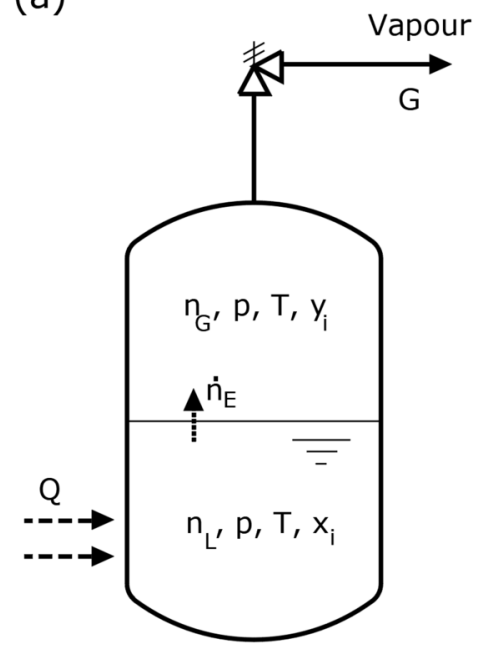

(b)

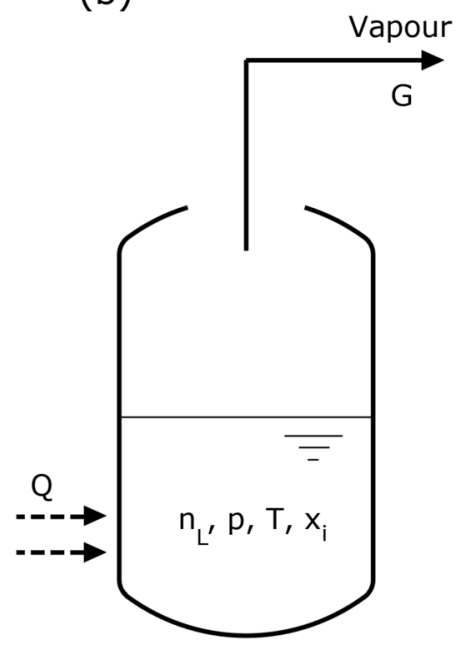


(a)

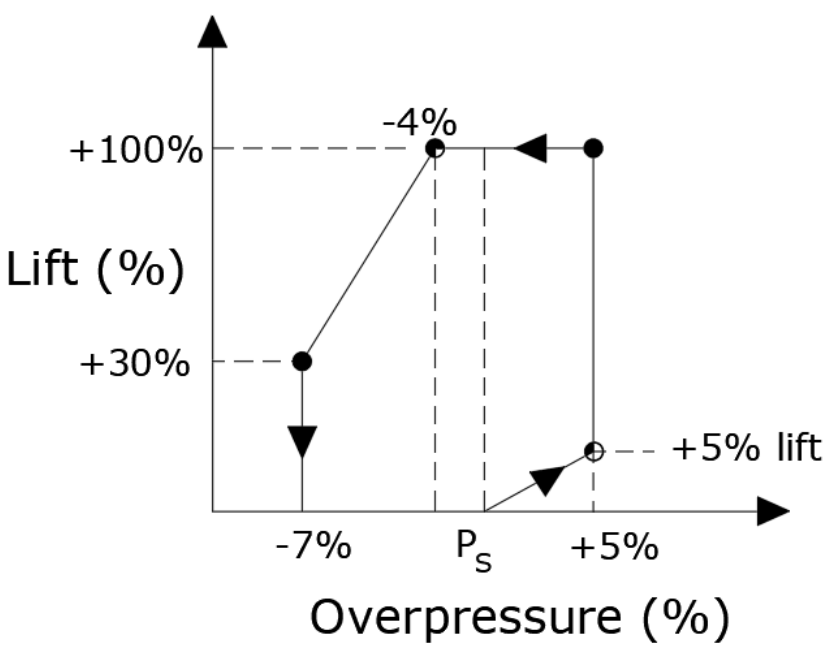

(b)

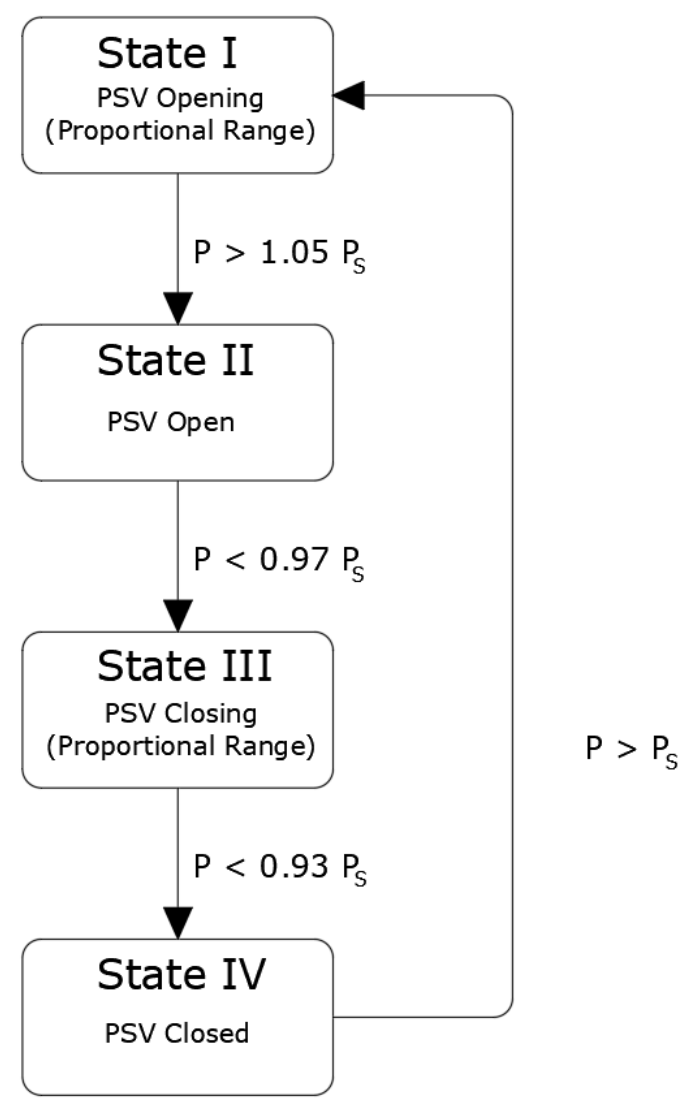


(a)

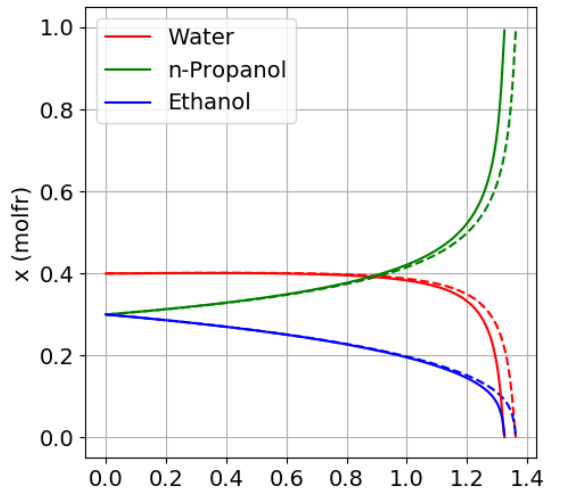

(c)

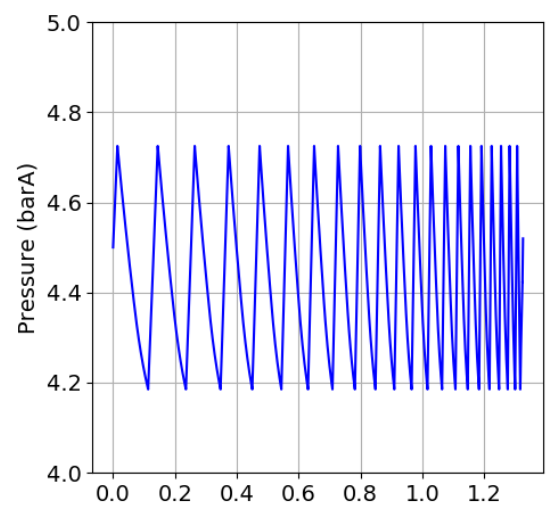

(e)

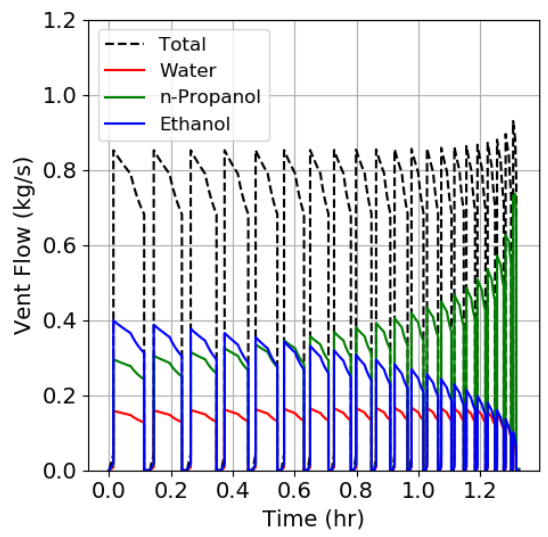

(b)

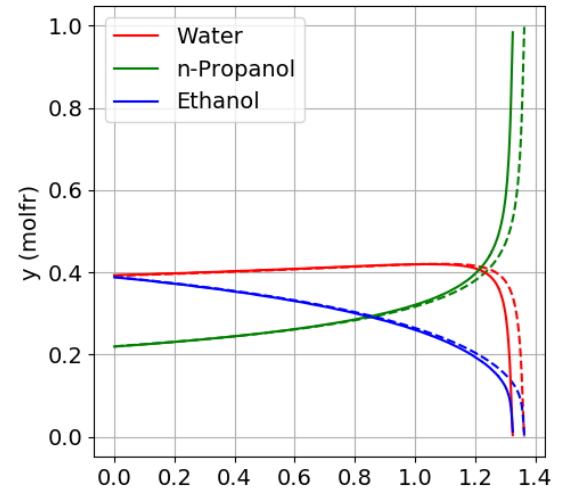

(d)

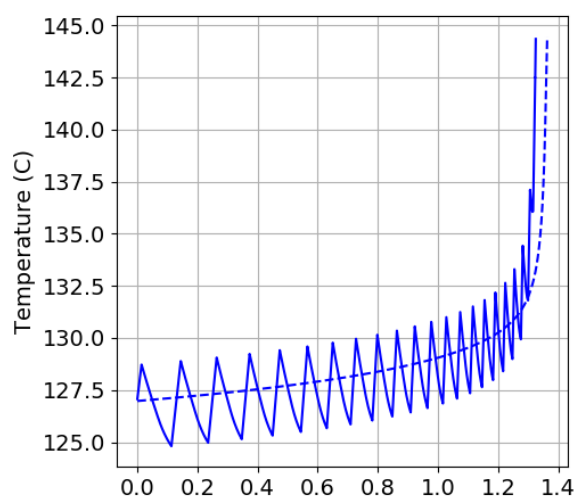

(f)

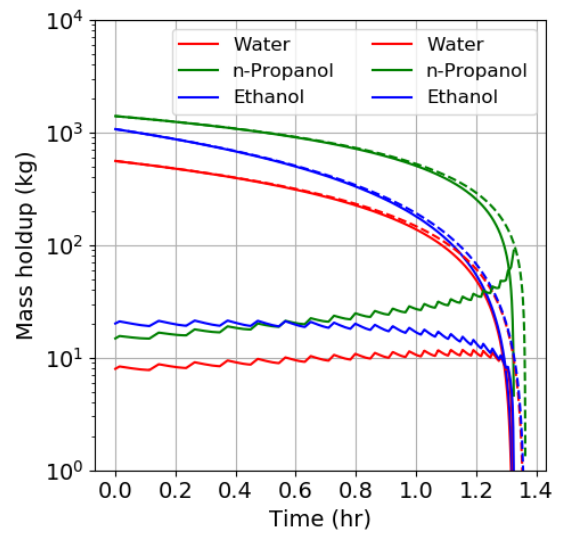


(a)

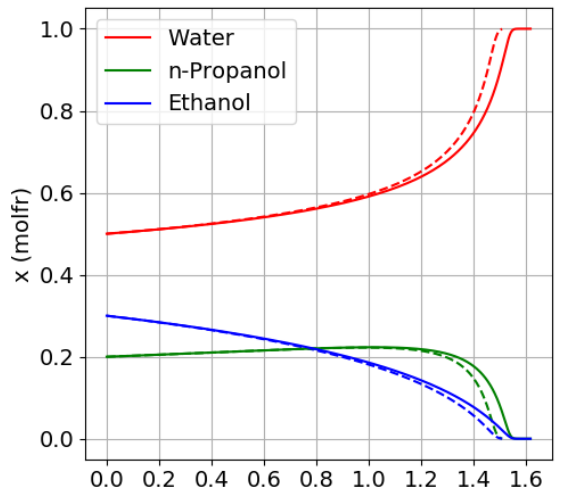

(c)

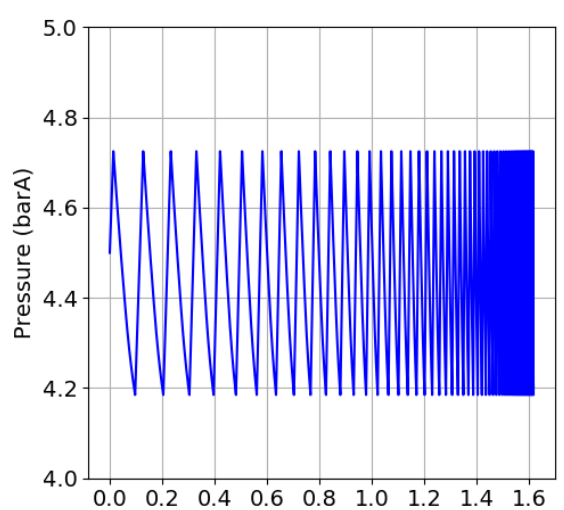

(e)

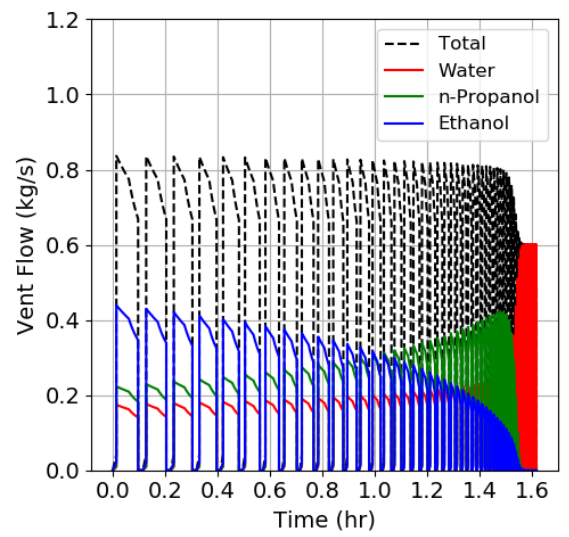

(b)

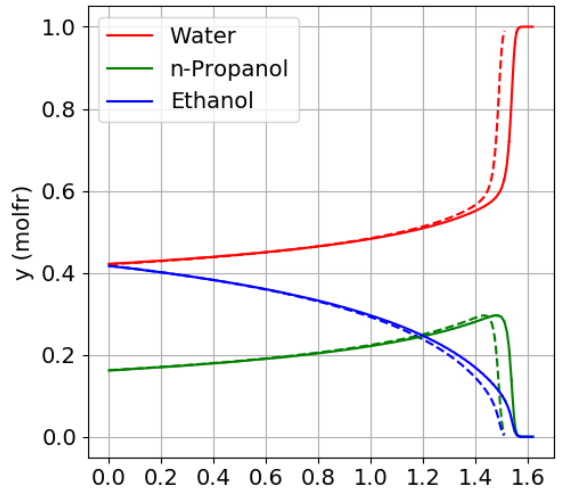

(d)

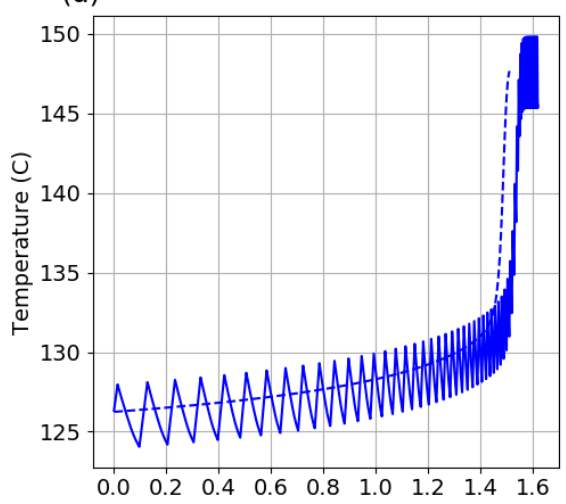

(f)

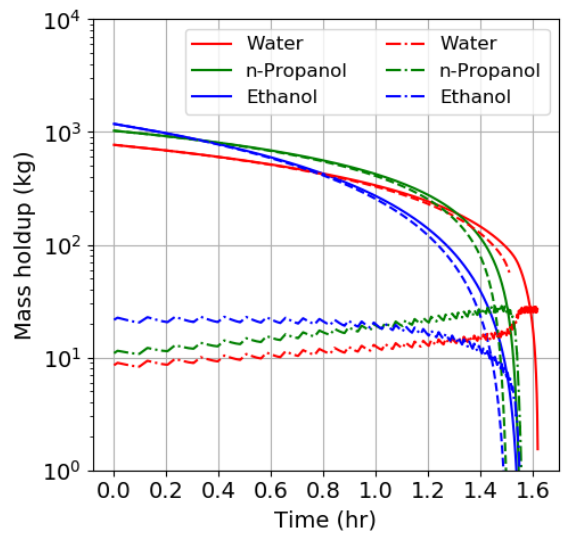




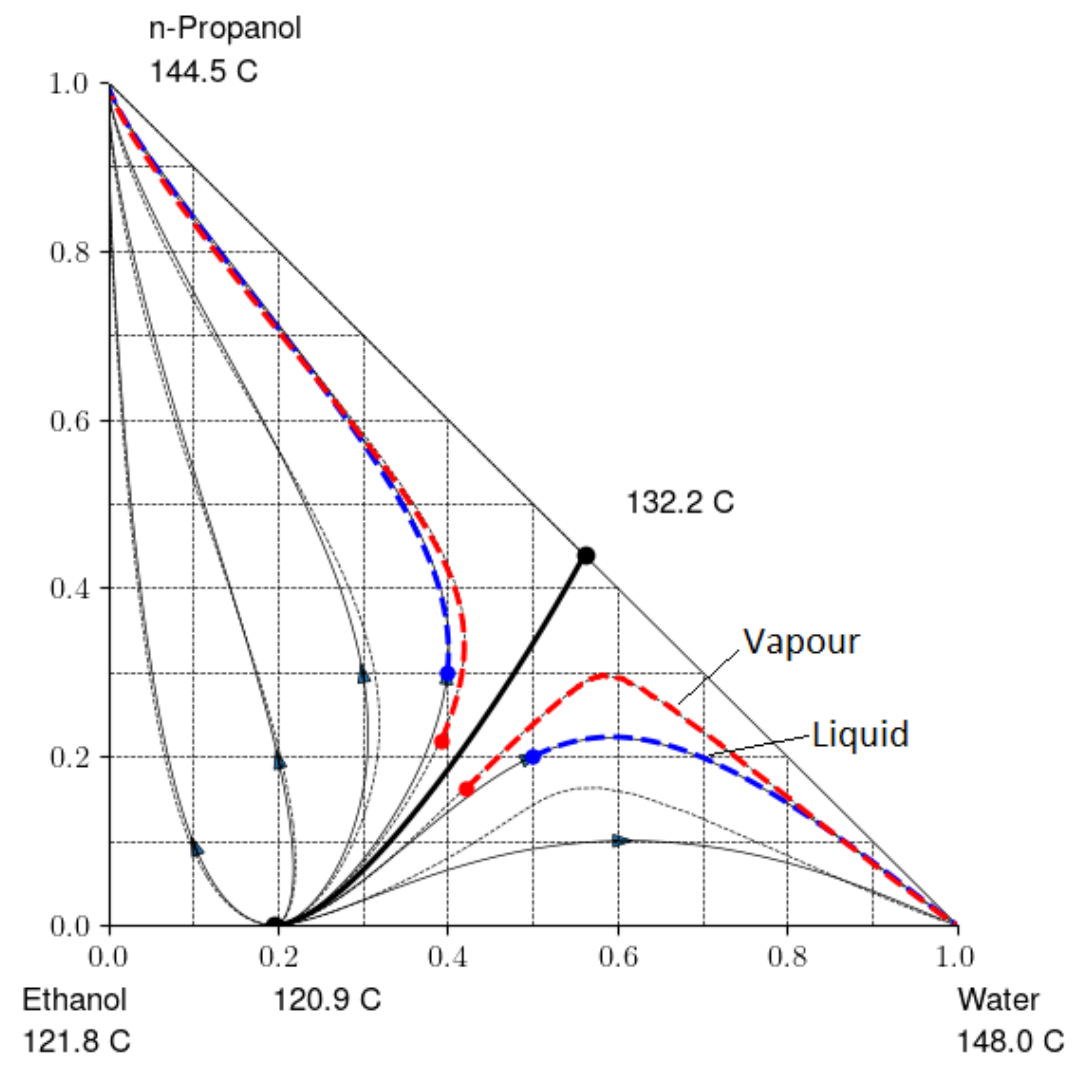




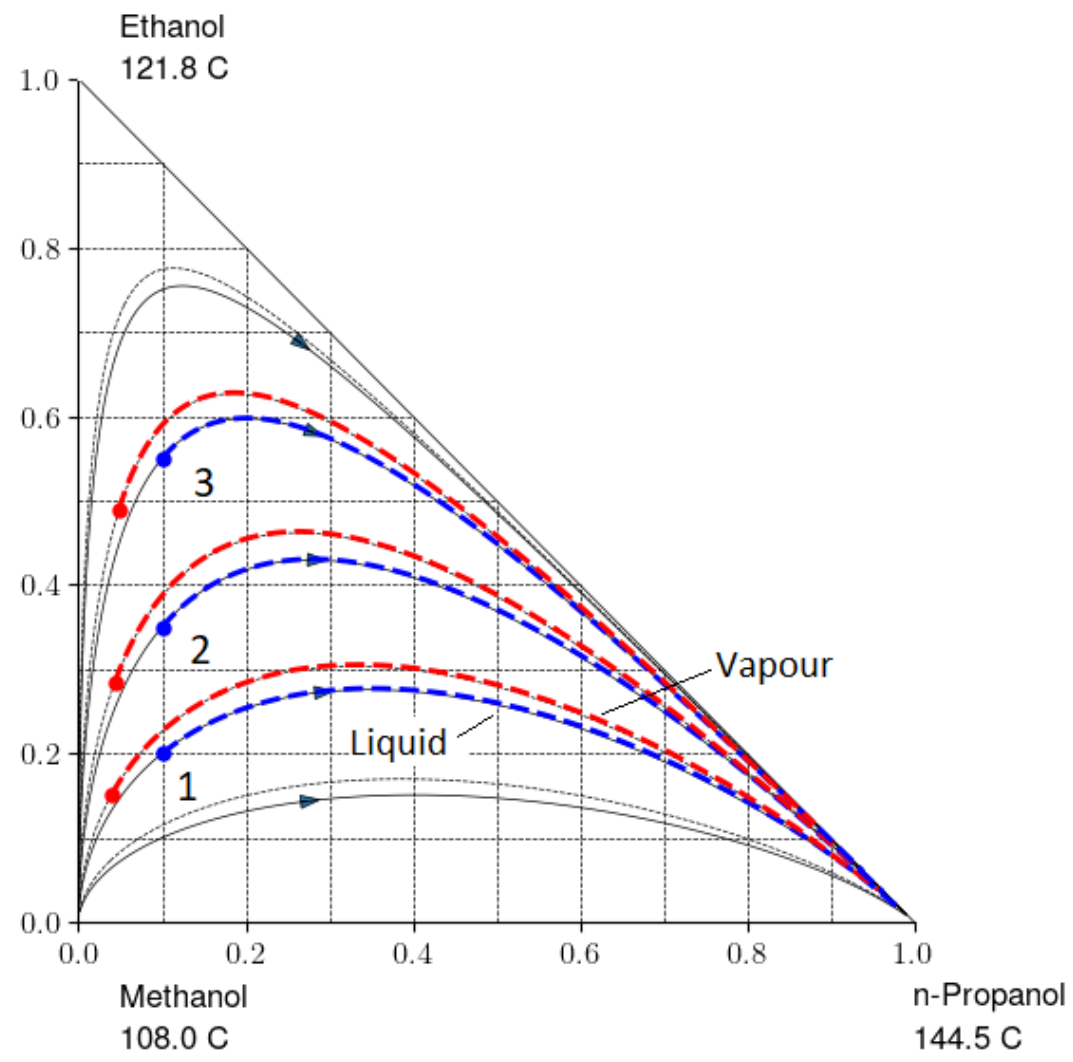




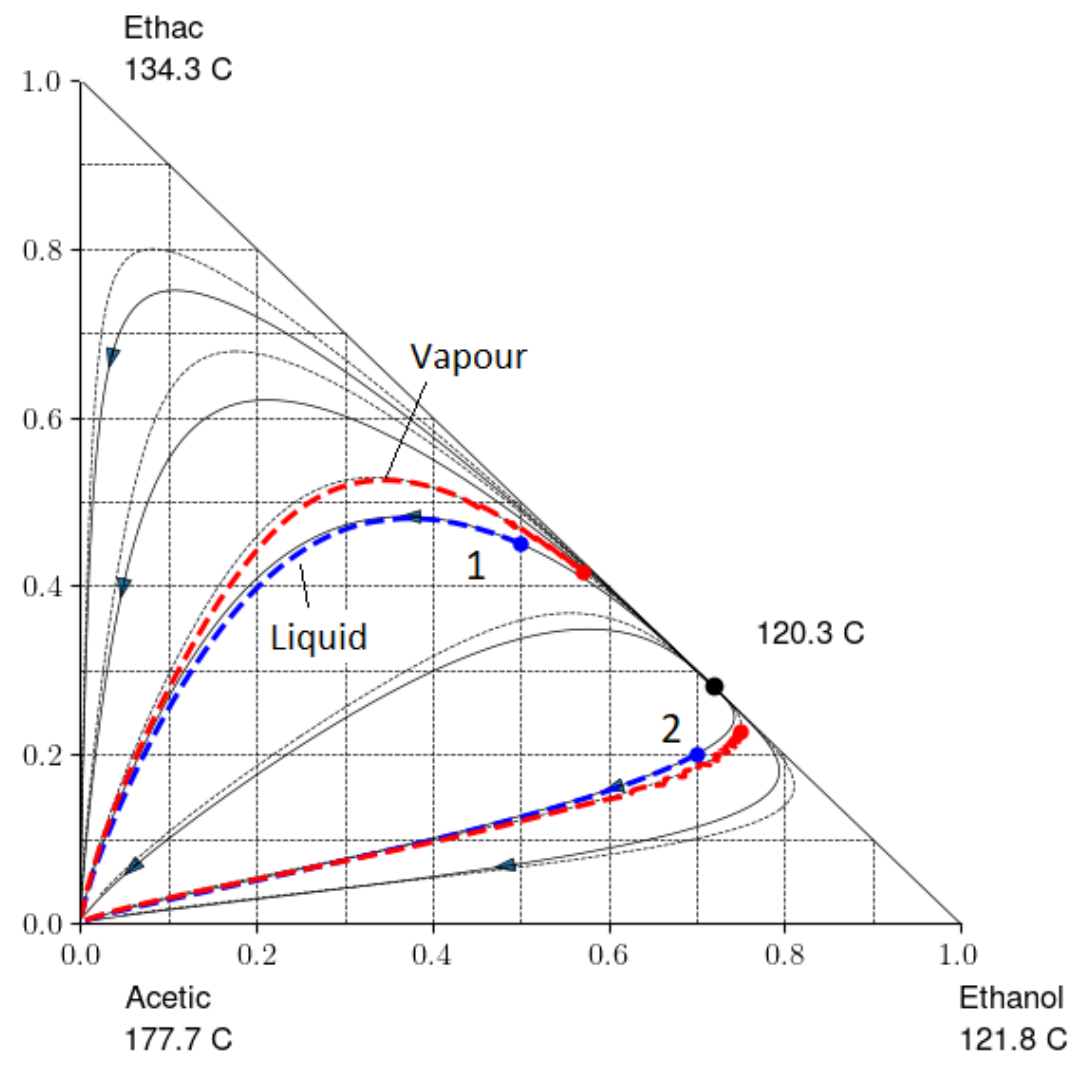




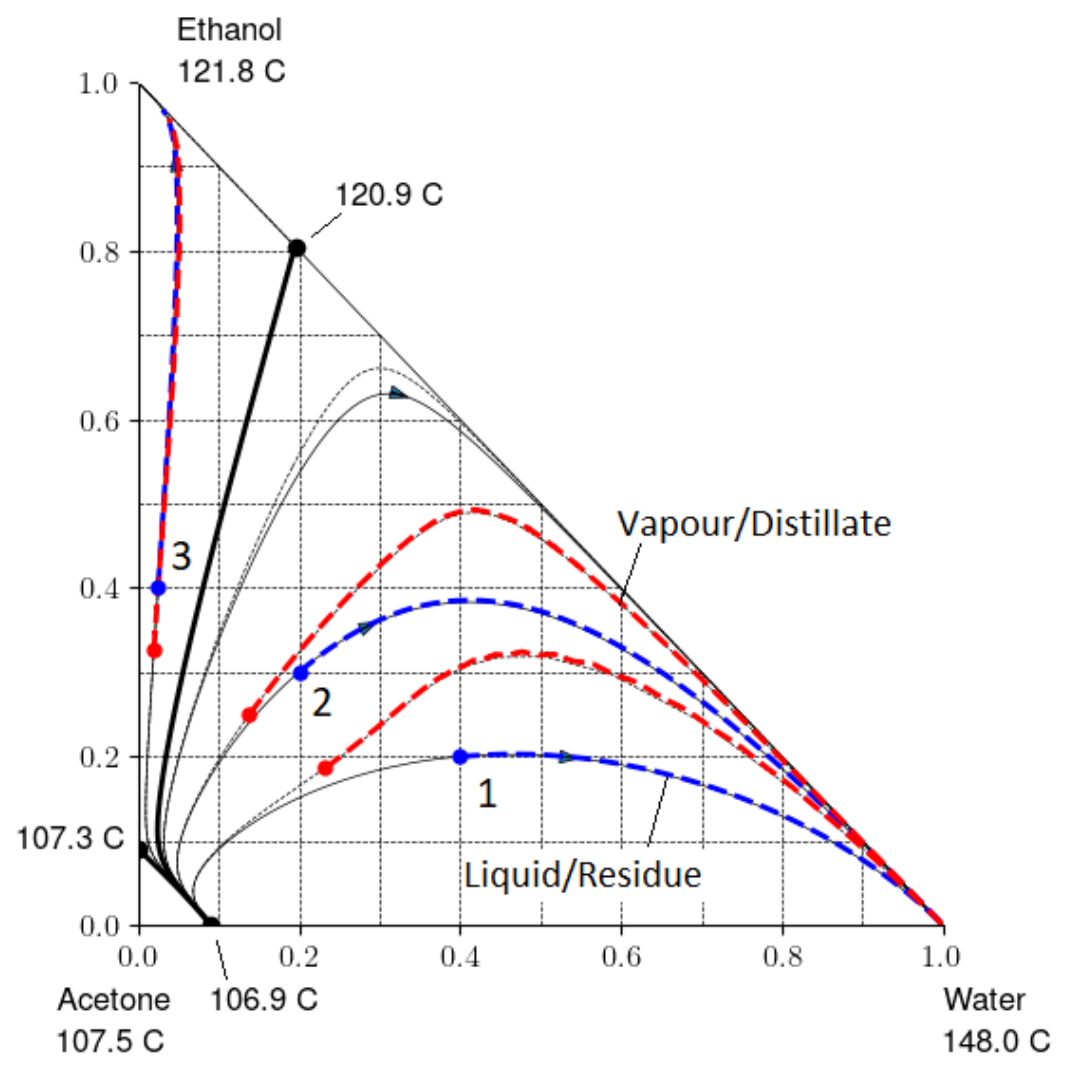




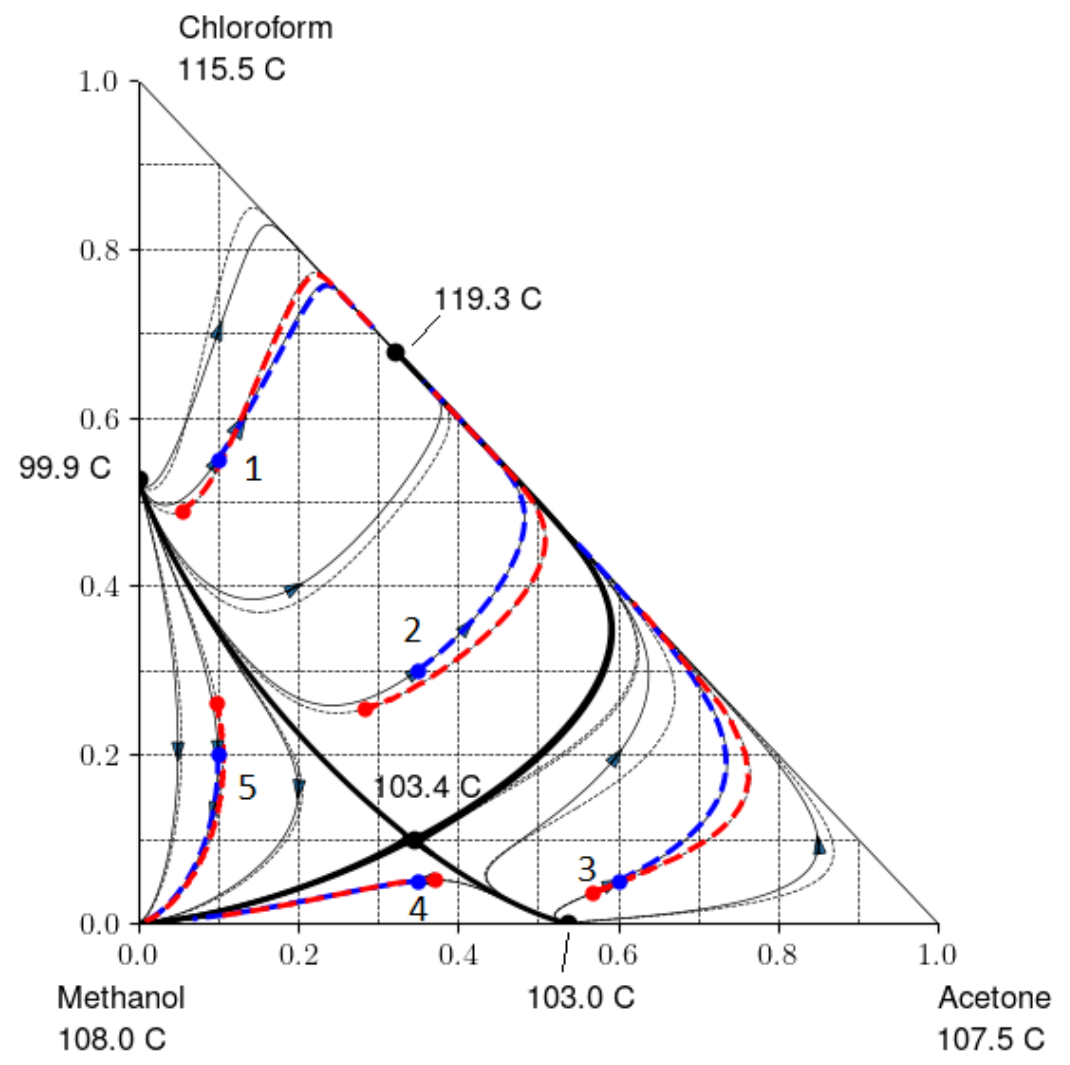




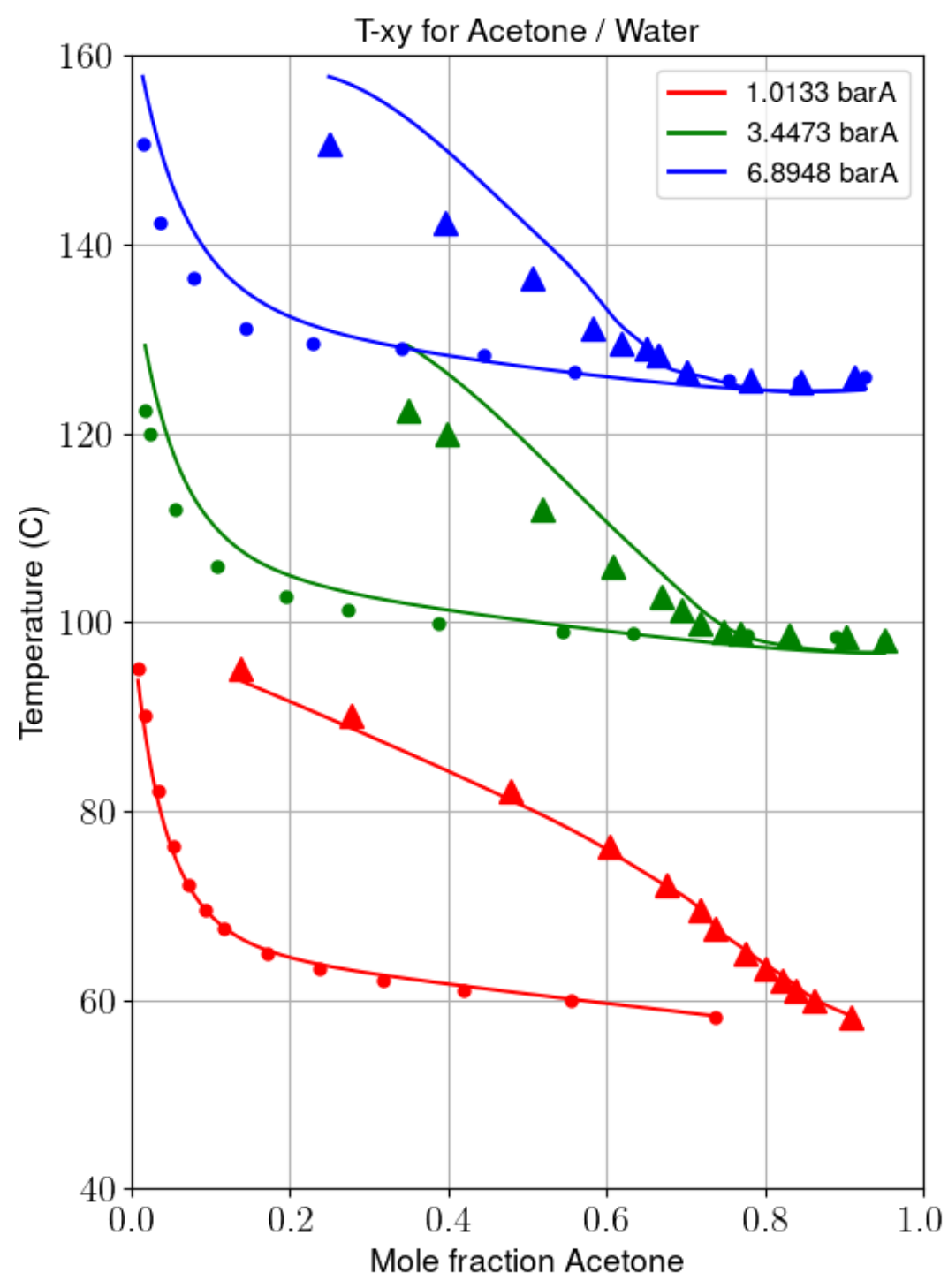




\section{Chloroform}

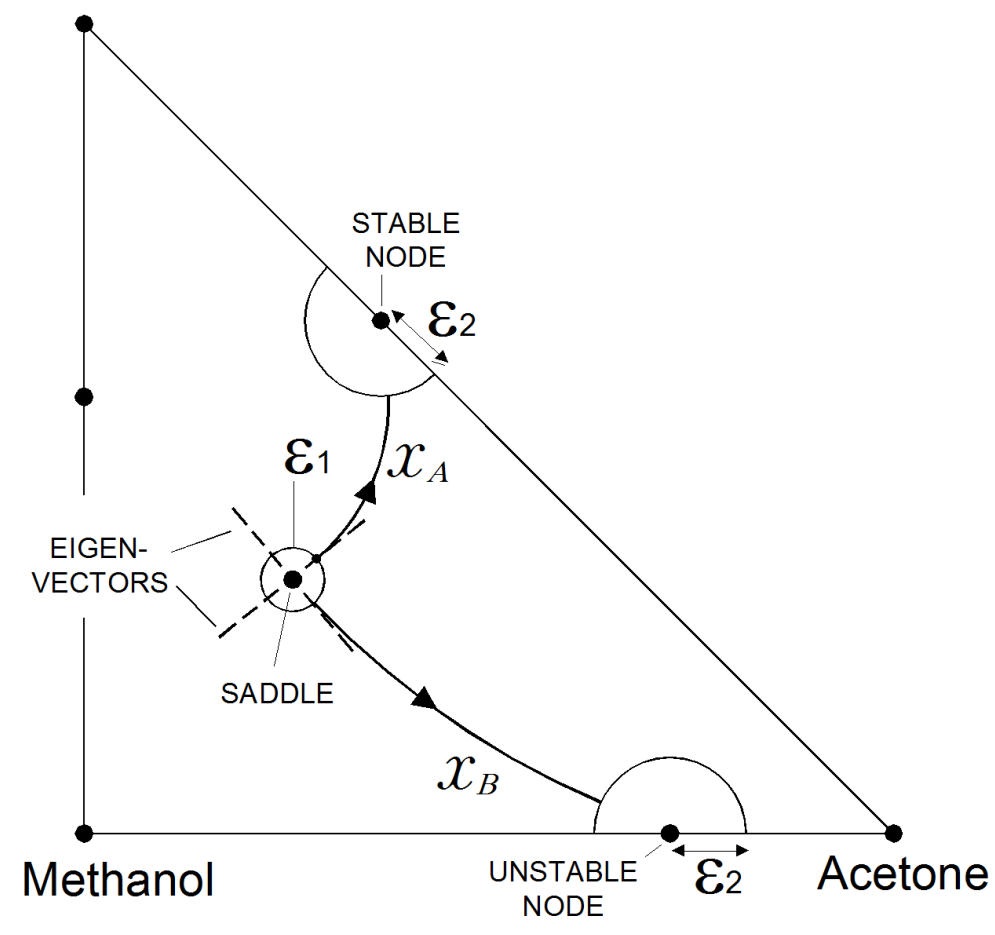




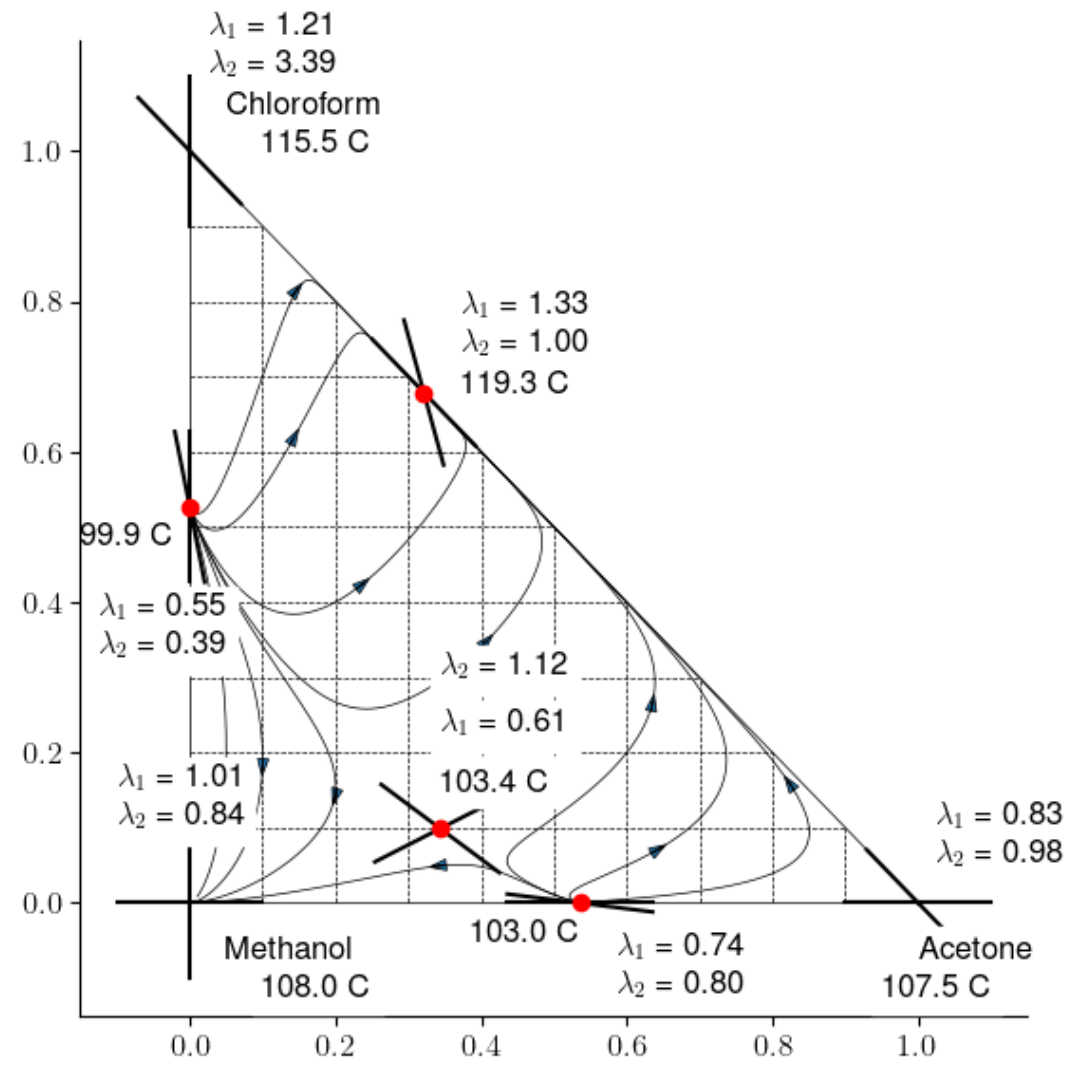

